\title{
Endoscopic sinus surgery for the removal of foreign body (root) from the maxillary antrum: Our experience
}

\author{
Mohammed Al Nashawany, Hassan Oluwafemi Olakunle, Ravi Kumar, \\ Humaid Alhumaid, Eman A Taha, Shaukat Parvez, Mohamed Sohbi
}

\begin{abstract}
Introduction: A 50-year-old edentulous patient was presented at the outpatient department with a two-year history of nasal regurgitation of fluids following a traumatic extraction and dislocation of the root into the left maxillary sinus. Examination revealed an oroantral fistula. This article describes the use of the functional endoscopic approach for the foreign body (root) removal as against the traditional Caldwell-Luc operation. This was followed-up with a twolayer soft tissue closure of the oroantral fistula resulting from the failed dental extraction.
\end{abstract}

Keywords: Endoscopy, Root, Maxillary antrum

Mohammed Al Nashawany ${ }^{1}$, Hassan Oluwafemi Olakunle ${ }^{2}$, Ravi Kumar ${ }^{3}$, Humaid Alhumaid ${ }^{4}$, Eman A Taha ${ }^{5}$, Shaukart Parvez ${ }^{6}$, Mohamed Sohbi ${ }^{7}$

Affiliations: ${ }^{1} \mathrm{MBBch}, \mathrm{Ms}$, IMRCS, Department of ENT surgery, KFSH, Buraidah, Quassim; ${ }^{2}$ BDS, FMCDS, Deparment of Oral and Maxillofacial surgery, KFSH, Buraidah, Quassim; ${ }^{3} \mathrm{MS}$, FRCS Ed, FRCS (ORL), Department of ENT surgery, KFSH, Quassim , Buraidah; ${ }^{4} \mathrm{MD}$ Otolarngol, Department of ENT surgery, KFSH, Buraidah, Quassim; ${ }^{5} \mathrm{MSc}$ Oral Surg, Deparment of Oral and Maxillofacial surgery, KFSH, Buraidah, Quassim; ${ }^{6}$ MDS, MOMSRCPS (Glasgow), Deparment of Oral and Maxillofacial surgery, KFSH, Buraidah, Quassim; ${ }^{7}$ MOSRCS Ed,MOMSRCPS (Glasgow), Department of Oral and Maxillofacial surgery, KFSH, Buraidah, Quassim.

Corresponding Author: Dr. Hassan Oluwafemi, Department of Oral and Maxillofacial Surgery, King Fahd Specialist Hospital, Quassim, Saudi Arabia; Tel: +966548597007; E-mail ID: drfemihassan@yahoo.com

Received: 12 January 2013

Accepted: 04 February 2013

Published: 04 February 2014

\section{How to cite this article}

Al Nashawany M, Olakunle HO, Kumar R, Alhumaid H, Taha EA, Parvez S, Sohbi M. Endoscopic sinus surgery for the removal of foreign body (root) from the maxillary antrum: Our experience. Case Rep Int 2014;3:1-5.

Article ID: 100003CRINTMN2014

$* * * * * * * * *$

doi:10.5348/crint-2014-3-CR-1

\section{INTRODUCTION}

Foreign bodies in the maxillary antrum are not common [1], it could result from penetrating trauma such as gun shot pellets, pieces of glass, stones. Alternatively, it could arise from iatrogenic sources whereby whole tooth, roots of teeth, gutta-percha, dental burs are inadvertently pushed into the antrum [1]. The main source of foreign body in the antum is the escape of teeth/roots during dental procedures [1].

Oroantral fistula is a pathologic communication between the oral cavity and the maxillary antrum [2]. A study by Lee et al. found that the roots of upper first molar were displaced into the maxillary sinus in about $75 \%$ of a series of 62 cases. Of these, palatal roots accounted for $76 \%$ [3]. Chongruk observed that extraction of the left maxillary first molar root appeared to be forced into the maxillary antrum more than the roots of other teeth [4].

The alveolar approach and the Caldwell-Luc operation are two well documented approaches for the removal of roots displaced into the maxillary antrum. The alveolar approach ensures the immediate removal of the displaced root via the oroantral opening, while the Caldwell-Luc operation involves bone removal from the canine fossa to gain access into the maxillary antrum after which the foreign body is removed [5]. 
Historically, the word 'endoscopy' was coined by a urologist, Antoine Jean Desormeaux $\left(1815^{-1894)}\right.$ at the beginning of the century in 1901, Hirshman used a modified cytoscope to inspect the maxillary sinus, he is today considered to be one of the pioneers of paranasal endoscopic surgery [6]. The ability to treat paranasal sinus disease has been revolutionalized by fibreoptic endoscopes because it allows the sinus air cells and sinus ostia to be opened up under direct visualization [7]. Applications of endoscopic sinus surgery include the treatment of chronic sinusitis refractory to medical treatment, nasal polyposis, sinus polyps, choanal atresia, cerebrospinal fluid leak closure, epistaxis control, biopsy and excision of selected tumors among a host of others. Advances in technology have made it possible to use the endoscopic approach to view and possibly remove foreign body from the antrum [8].

The aim of this article is to present the case of a root dislocated into the maxillary antrum solely removed through functional endoscopic sinus surgery.

\section{CASE REPORT}

A healthy 50-year-old female was presented at the outpatient department with a history of nasal regurgitation of fluids and feeds and symptoms of recurrent maxillary sinusitis following a traumatic dental extraction two years previously. There was no significant medical history.

The crown was fractured during extraction and while attempting to elevate the root, it was inadvertently pushed into the left antrum. The root had been in the maxillary antrum for a duration of more than two years. She had undergone two surgeries for fistula closure but none had succeeded. No attempts were made at these times to remove the foreign body from the antrum.

Intraoral examination showed the patient to be edentulous, except for the presence of 32,33 with an oroantral fistula measuring about $1.5 \mathrm{~cm}$ in diameter in the region of the left maxillary first molar. This had been tolerated for this length of time because the patient was a denture wearer. The presence of fistula was established on the nose blow test and the use of probe into the left maxillary antrum through the fistula. Endoscopic examination of the nose showed pus in the left middle meatus which on suction exposed edematous, polypoidal mucosa. A coronal computed tomography (CT) scan of sinuses revealed opacification of the left maxillary antrum and the presence of a foreign body in the centre of the left maxillary sinus (Figure 1).

The treatment plan was for endonasal endoscopic sinus surgery with left middle meatal antrostomy to retrieve the foreign body (root) and a two-layer soft tissue closure of the oroantral fistula.

General anesthesia was administered via oral intubation, using hypotensive technique. A Hopkins rod endoscope (o-degree) was introduced via the left nostril. Middle meatal antrostomy was done and the natural ostium was widened to allow wide access into the left maxillary sinus. The displaced roots along with friable infected mucosa were removed and sent for histopathology (Figure 2). The sinus was irrigated and inspected with the aid of a 30-degree endoscope, ensuring a clean sinus cavity and an antral pack was placed. Buccal myomucosal flap was raised as part of a two-layer soft tissue closure to seal the oroantral fistula (Figure 3).

The postoperative period was uneventful, it included a course of broad-spectrum antibiotics, nasal drops and

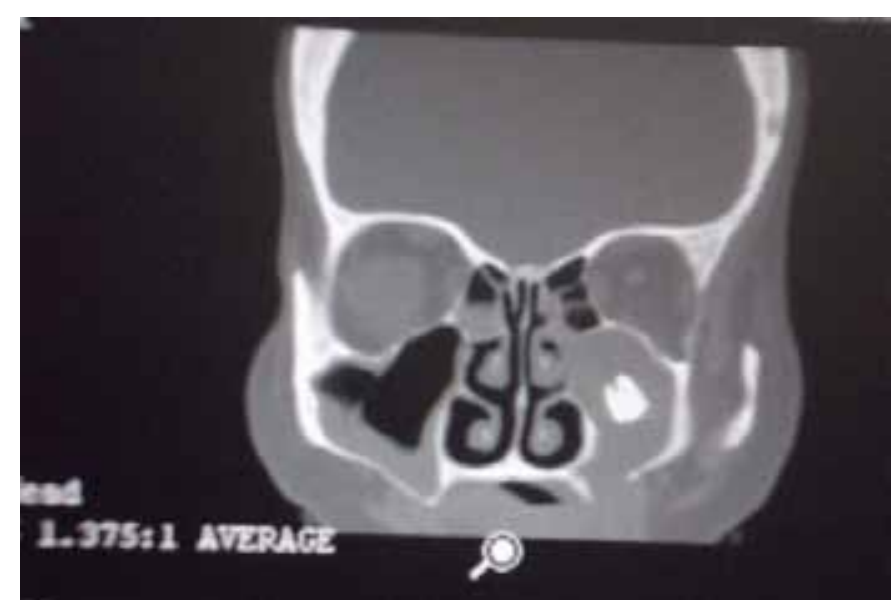

Figure 1: Preoperative computed tomography scan of sinuses.

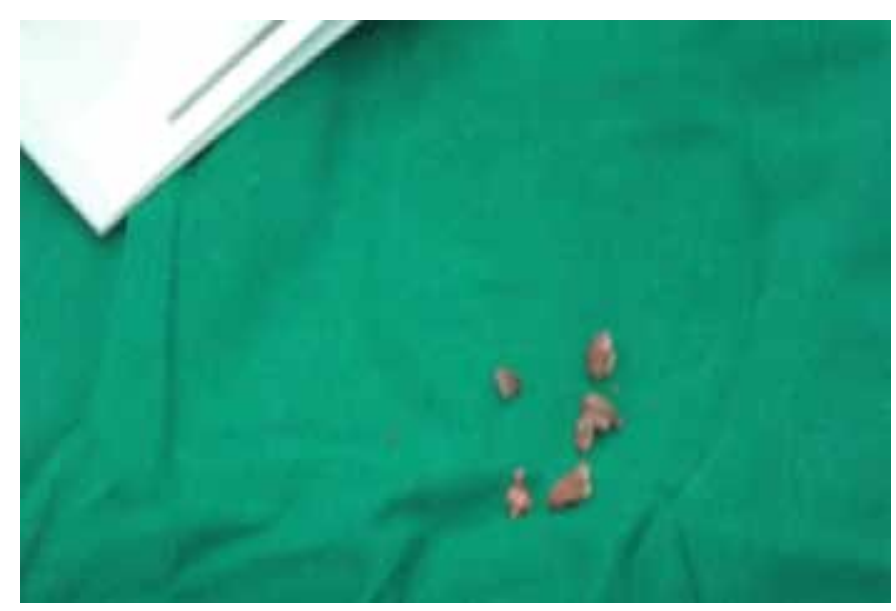

Figure 2: Roots following endoscopic surgery.

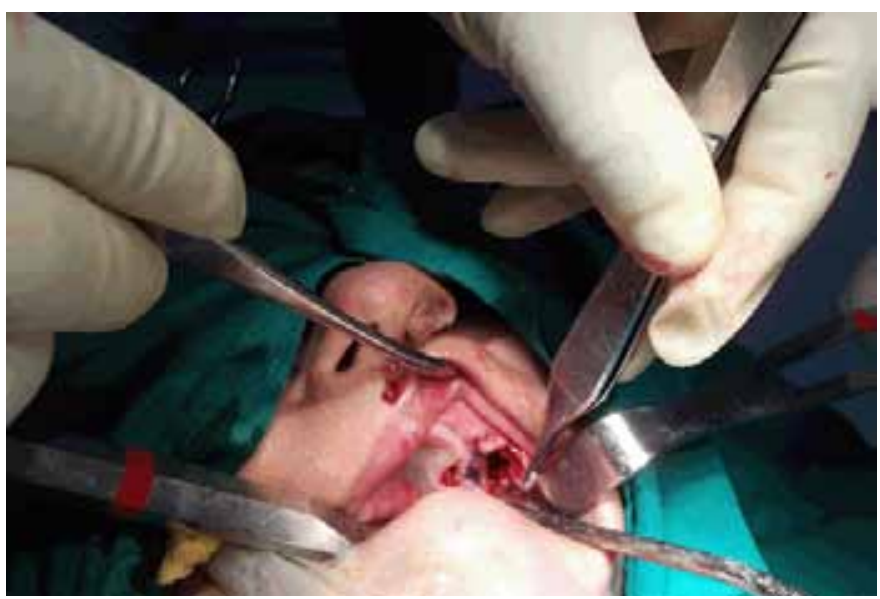

Figure 3: Closure of oroantral fistula intraoperative view. 
inhalants and the patient was instructed not to blow the nose next five days. The patient was discharged home within 48 hours. Postoperative CT scan showed that the maxillary antrum was clear of the foreign body (Figure 4). The patient had a second surgery (vestibuloplasty) to aid retention and stability of a new prosthesis (Figure 5 and Figure 6).

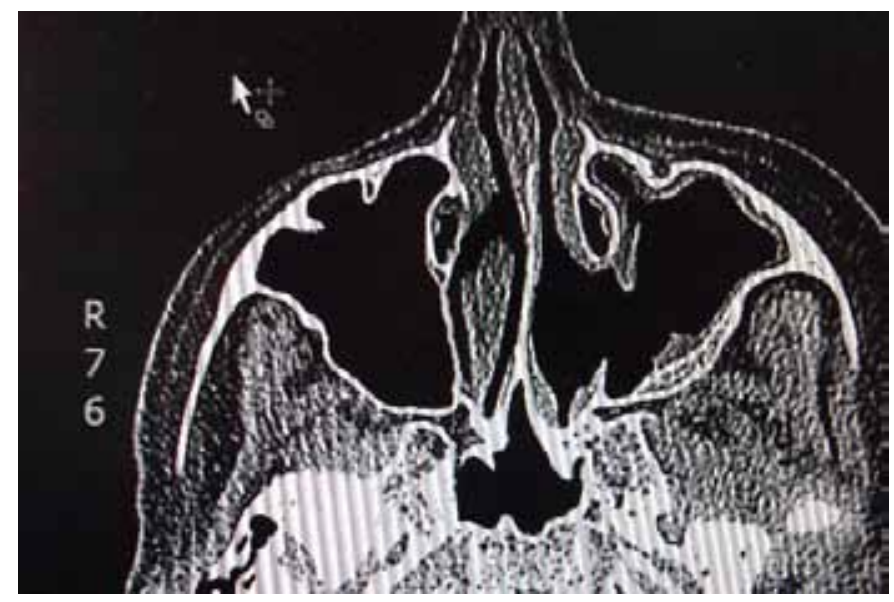

Figure 4: Postoperative computed tomography scan of the patient.

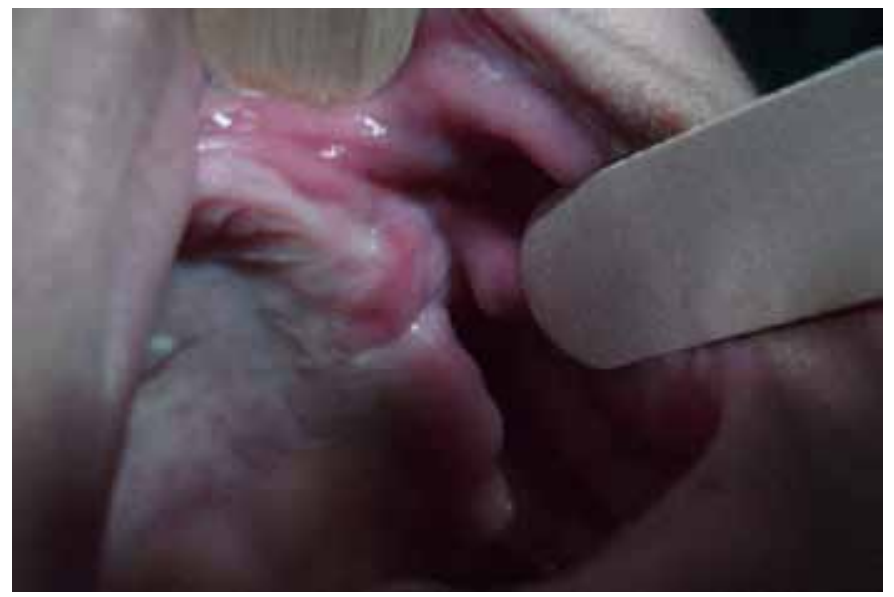

Figure 5: Edentulous ridge following closure oroantral fistula.

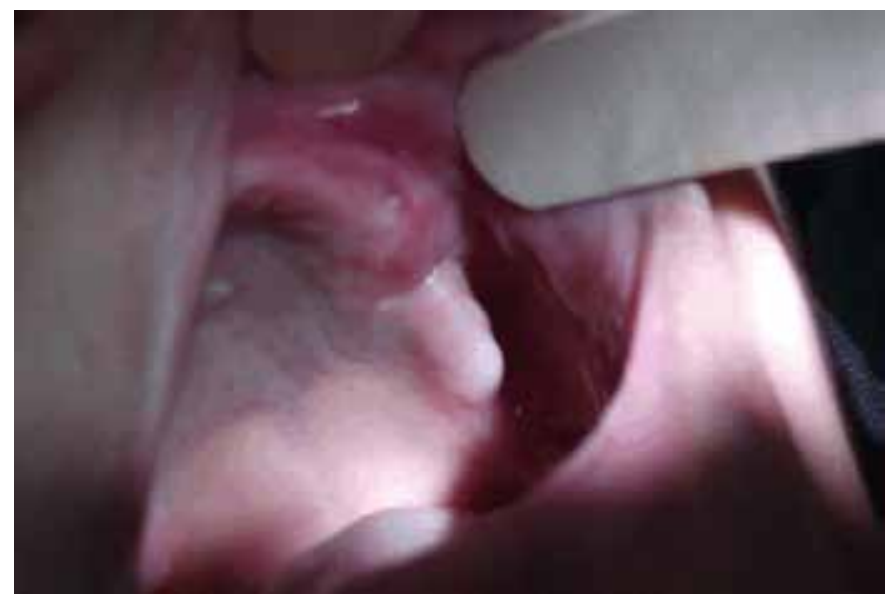

Figure 6: Edentulous ridge following closure of oro-antral fistula.

\section{DISCUSSION}

Foreign bodies in the maxillary antrum whatever the origin are rare, the most common cause being roots accidentally displaced in the process of tooth extraction $[1,5]$. A study of oroantral fistula by Armantunga revealed that the most common site of fistula was the upper first molar region. These fistulae were found to be twice as common in males as females. The fistulae are rare in children as the volume of the maxillary sinus is small. Most fistulae occur in people over the age of 30 years [9].

These patients may present with history of dental extractions, recurrent maxillary sinusitis, nasal regurgitation of fluids; the patient feels it entering the nose and sometimes running out of the nose. When the patient is asked to blow the closed nose, air hisses through the fistulae into the mouth. When patient blows out the cheeks, air passes from the mouth into the sinus and nasal cavities (Valsalvin test),. Endoscopic examination of the nose usually reveals pus in the middle meatus and other signs to suggest maxillary sinus pathology such as congestion, edema, polyps or granulations [2].

There are two notable surgical approaches in literature for the removal of a displaced root from the maxillary antrum. The alveolar approach and the CaldwellLuc operation. The alveolar approach is based on the principle that most roots fall to the floor of the maxillary sinus or in the immediate vicinity of the socket, retrieval of the root and the closure of the fisula are done at the same operation. This approach, however, is not suitable for cases of dislocated roots between the apices of the standing vital teeth or for those impacted in the nasal ostium [5]. The alveolar approach was not an option here since the root was centrally placed in the antrum and far from the antral floor. In addition, widening the defect in the floor of the antrum given the history of recurrent purulent discharge may result in flap failure.

The Caldwell-Luc approach has been in use for more than 100 years and has remained the work horse of sinus surgery [5, 10], Advantages of this procedure include better access to recover root fragment $[8,9]$ and excellent view of the tooth/roots impacted in the nasal ostium [7, 8]. There are many disadvantages which include facial pain and numbness from injury to the infraorbital nerve $[7,8]$ and anesthesia or paresthesia of the upper anterior teeth due to damage to the anterior superior alveolar nerve while bone is being removed from the canine fossa $[7,8]$. Functional endoscopic surgery tries to overcome these drawbacks $[7,8]$.

Functional endoscopic sinus surgery gained popularity in the 1990 s $[6,7,10]$. It has been used extensively for recurrent sinusitis, antrochonal polyps, sinus mucoceles, orbital decompression, e.g., Graves' opthalmopathy, optic nerve decompression, dacrocystorhinostomy, choanal atresia and foreign body removal [8]. Most of the reports on foreign body removal were described in combination with the Caldwell-Luc procedure. Costa et al. [11] described the use of an endoscopically assisted 
Caldwell-Luc procedure in removing a residual dental cement from the maxillary antrum, while Friedrich and Ritternberg [12] described a combined approach for the removal of a dental bur from the antrum. Chandrasena et al. [13] on the other hand reported the sole use of the functional endoscopic technique for the retrieval a root inadvertently displaced into the antrum by a general practitioner; a procedure very similar to the approach described in this article. This was also the first report in literature where an endoscope was used solely to remove a root from the maxillary antrum. Abdulsalam et al. in their report of an endoscopic removal of an ectopic third molar obstructing the osteomeatal complex used this technique in not only removing the tooth but in addition teasing out an associated dentigerous cyst, thereby restoring the patient's normal breathing [14].

The advantages of functional endoscopic sinus surgery noted in literature include its less invasiveness, decreased risk of tooth root injury and ability to fully visualize the antrum, others include a short recovery time and little or no risk of injury to the infraorbital nerve [11-14]. The potential problem of altered facial growth in children associated with the Caldwell-Luc operation is absent with this technique $[15,16]$.

A successful endoscopic surgery requires an experienced operator, it also takes longer surgical time compared to the traditional Caldwell-Luc operation [7, 10-12]. We found this approach easier given the fact that the ENT team was led by a very experienced endoscopic surgeon.

\section{CONCLUSION}

Oroantral fistula are usually secondary to dental procedures, whatever the foreign body, it must be removed even if asymptomatic. The Caldwell-Luc approach has been used sucessfully for more than 100 years. Advances in technology with minimal access surgery has brought to fore newer modalities of treatment which has made what was previously thought impossible possible. A multidisciplinary approach to the management will improve outcome with less morbidity. This is one of the few cases in literature where a root displaced into the maxillary antrum was removed via the nostril by endoscopic approach.

$* * * * * * * * *$

\section{Author Contributions}

Mohammed Al Nashawany - Substantial contributions to conception and design, Acquisition of data, Analysis and interpretation of data, Drafting the article, Revising it critically for important intellectual content, Final approval of the version to be published

Hassan Oluwafemi Olakunle-Analysis and interpretation of data, Revising it critically for important intellectual content, Final approval of the version to be published
Ravi Kumar - Analysis and interpretation of data, Revising it critically for important intellectual content, Final approval of the version to be published

Humaid Alhumaid - Analysis and interpretation of data, Revising it critically for important intellectual content, Final approval of the version to be published

Eman A Taha - Analysis and interpretation of data, Revising it critically for important intellectual content, Final approval of the version to be published

Shaukat Parvez - Analysis and interpretation of data, Revising it critically for important intellectual content, Final approval of the version to be published

Mohamed Sohbi - Analysis and interpretation of data, Revising it critically for important intellectual content, Final approval of the version to be published

\section{Guarantor}

The corresponding author is the guarantor of submission.

\section{Conflict of Interest}

Authors declare no conflict of interest.

\section{Copyright}

(C) 2014 Mohammed Al Nashawany et al. This article is distributed under the terms of Creative Commons Attribution License which permits unrestricted use, distribution and reproduction in any medium provided the original author(s) and original publisher are properly credited. Please see the copyright policy on the journal website for more information.

\section{REFERENCES}

1. Alex MM, Arun NB, Shantanu T, Ophelia D. Penetrating foreign body in the maxillary sinus and pterygopalatine fossa. Report of a rare case. Internet Journal of Head and Neck Surgery 2010;4(1).

2. Yilmaz T, Suslu AE, Gursel B. Treatment of Oro-antral Fistula: Experience With 27 cases. Am J Otolarngol 2003;24(4):221-3.

3. Lee FM. Management of the displaced root in the maxillary sinus. Int J Oral Surg 1978;7(4):374-9.

4. Chongruk C. [Radiographs and tooth roots in maxillary sinus]. J Dent Assoc Thai 1989;39(3):8895.

5. Ong AH. Caldwel-Luc Approach For Surgical Removal Of The Root From The Maxillary Sinus With Closure Of Oro-antral Fistula. Annals Dent Univ Malaya 1997;4:49-51.

6. Doglietto F, Prevedello DM, Jane JA Jr, Han J, Laws ER Jr. Brief history of endoscopic transsphenoidal surgery--from Philipp Bozzini to the First World Congress of Endoscopic Skull Base Surgery. Neuro surg Focus 2005;19(6):E3.

7. Slack R, Bates G. Functional endoscopic sinus surgery. Am Fam Physician 1998 Sep 1;58(3):707-18.

8. Ankit P, Meyers AD. Introduction to functional endoscopic sinus surgery. Medscape reference 2012. 
9. Amaratunga NA. Oro-antral fistulae--a study of clinical, radiological and treatment aspects. Br J Oral Maxillofac Surg 1986;24(6):433-7.

10. Guliati SP, Gulia JS, Hooda A. Safety of Fess In Maxillary Sinus Foreign Body Removal In Children. The Internet Journal of Dental Science 2009;6(2).

11. Costa F, Robiony M, Toro C, Sembronio S, Politi M. Endoscopically assisted procedure for removal of a foreign body from the maxillary sinus and contemporary endodontic surgical treatment of the tooth. Head Face Med 2006;2:37.

12. Friedrich J, Rittenberg BN. Endoscopically assisted Caldwell-Luc procedure for removal of a foreign body from the maxillary sinus. J Can Dent Assoc 2005;71(3):200-1.
13. Chandrasema F, Singh A, Visavadia BG. Removal of a root from the maxillary sinus using functional endoscopic sinus surgery. Br J Oral and Max fac Surg 2010;48(7):558-9.

14. Hasbini AS, Hadi U, Ghafari J. Endoscopic removal of an ectopic third molar obstructing the osteomeatal complex. Ear Nose Throat J 2001;80(9):667-70.

15. Wolf G, Anderhuber W, Kuhn F. Development of the paranasal sinus in children. Implications of paranasal sinus surgery. Ann Otol Rhinol Laryngol 1993;102(9):705-11.

16. Mair EA, Bolger WE, Breisch EA. Sinus and facial growth after paediatric endoscopic sinus surgery. Arch Otolaryngol Head Neck Surg 1995;121(5):547-2.
Access full text article on other devices

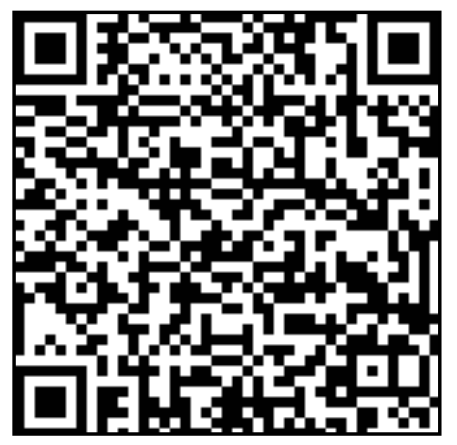

Access PDF of article on other devices

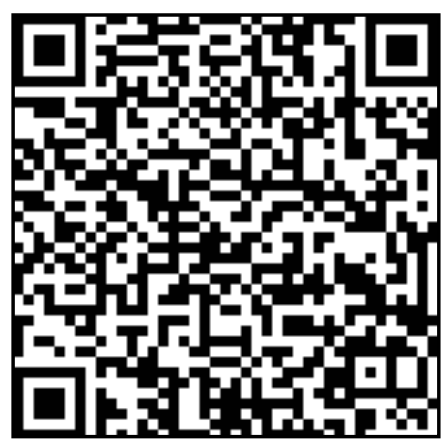

